\title{
Study of Genetic Diversity in Some Newly Developed Rice Genotypes
}

\author{
Vangaru Sathish ${ }^{*}$ and Bijoy Kumar Senapati \\ Department of Genetics and Plant Breeding, Bidhan Chandra Krishi Viswavidyalaya, \\ Mohanpur-741252, West Bengal, India \\ *Corresponding author
}

\begin{abstract}
A B S T R A C T
In the present study, forty-nine rice genotypes consisting of high yielding rice genotypes were raised at Regional Research Sub Station, Chakdah, during Kharif-2014 to evaluate and identify diverse genotypes for twenty yield and yield attributing characters using the

Keywords

Rice, Yield, Genetic diversity, $\mathrm{D}^{2}$ statistic and cluster.

Article Info

Accepted:

23 September 2017

Available Online:

10 October 2017

$\mathrm{D}^{2}$ statistic. Among six clusters, cluster-II was the largest with 28 genotypes followed by cluster-I and cluster-III with 10 and 5 genotypes respectively and cluster-IV, V \& VI each with two genotypes. Highest inter cluster generalized distance (1957.68) was between cluster- IV and cluster-V followed by cluster-III and IV (1954.27), cluster-I and IV (1779.21) and cluster-II and IV (1549.69) specifying that genotypes included in these clusters were genetically diverse and would give rise high heterotic response, while the lowest inter cluster was 587.86 found between cluster-I and cluster-V indicating close relationship among the genotypes included in these clusters. The intra cluster distance was maximum in cluster-III (684.04) followed by Cluster-II (646.28) and cluster-I (630.83) indicates hybridization of genotypes within this cluster may result in good cross combinations. Among the twenty traits studied, maximum contribution was made by harvest index and (27.466\%) and seed yield per plant $(26.105 \%)$, these characters may be given importance during hybridization programme.
\end{abstract}

\section{Introduction}

Rice (Oryza sativa L. 2n: 2X: 24) is the most important cereal crop cultivated widely in many parts of the world. Genus Oryza belongs to the tribe Oryzeae in the family Poaceae. Out of the 24 species of rice, 22 species are wild and only 2 species are cultivated i.e., $O$. sativa and $O$. glaberima. As a cereal grain, it serves as staple food for 2.5 billion people and growing rice is the largest single use of land for producing food, covering nine percent of the earth's arable land (Khan et al., 2009). More than 90 per cent of the rice is produced and consumed in Asian countries. It ranks third in the production of agricultural commodity. In 2015 , the world rice production was $478.8 \mathrm{~m}$ tons. In India about 44.6 million ha area is under rice cultivation and produced 90 million tonnes (Venkatesan et al., 2017). The FAO forecasts that, global production will need to increase by over $40 \%$ by 2030 and 70 $\%$ by 2050 (FAO, 2009). Exploitation of Heterosis will help to further improve the yields of rice. The more diverse the parents, the greater are the chances of obtaining higher amount of heterotic expression in F1's and broad spectrum of variability in segregating generations (Doddabhimappa et al., 2014). 
Genetic divergence among the genotypes plays an important role in the selection of parents having wider variability for different yield and yield attributing characters Sarawgi and Rita (2007) Therefore, in the present study, an attempt was made to assess the genetic divergence using Mahalanobis $\mathrm{D}^{2}$ statistics and different clustering procedures, based on yield and yield attributing characters and assessing the relative contribution of different components to total divergence.

\section{Materials and Methods}

The present experiment was carried out to study genetic diversity of 49 genotypes including check varieties Dhanrasi, MTU70261 and Swarna Sub 1 during Kharif 2014. The experiment was carried out in field of Regional Research Sub Centre, Chakdah, Bidhan Chandra Krishi Viswa vidyalaya, Nadia, West Bengal. The Experimental material comprised of 49 genotypes were collected from Initial Varietal Trail- Rainfed Shallow Low Land (IVT-RSL). Experiment was laid out in Randomized Block Design with two replications. Recommended cultural practices were followed to grow the healthy crop. Five plants were selected randomly from each genotype in each replication to record the yield and its attributing characters viz., Days to $50 \%$ flowering Days to maturity, Plant height $(\mathrm{cm})$, No. of panicles per plant, Panicle weight $(\mathrm{g})$, Panicle length $(\mathrm{cm})$, No. of primary branches per panicle, No. of secondary branches per panicle, No. of florets per panicle, No. of grains per panicle, Floret fertility (\%), 1000 grain weight (g), Grain length $(\mathrm{mm})$, Grain breadth $(\mathrm{mm})$, Grain $1 / \mathrm{b}$ ratio $(\mathrm{mm})$, Kernel length $(\mathrm{mm})$, Kernel breadth $(\mathrm{mm})$, Kernel $1 / \mathrm{b}$ ratio, Harvest index $(\%)$ and Seed Yield/plant (g).

The genetic distance between the genotypes using Multivariate analysis was done as per Mahalanobis (1936) $\mathrm{D}^{2}$ statistic described by
Rao (1952) and the genotypes were grouped into different clusters following Tocher's method. Contribution of each character for genetic divergence was estimated from the number of times it appeared in first rank. These parameters were estimated using GenRes Ver.4.0 software. The $\mathrm{D}^{2}$ values between any two genotypes were calculated as the sum of squares of the differences between the mean values of all the 20 characters and used for the final grouping of the genotypes.

\section{Results and Discussion}

Analysis of variance (Table 1) revealed presence of significant variability among the genotypes for all the characters studied. Based on $\mathrm{D}^{2}$ values, the genotypes were grouped into six highly divergent clusters (Table 2). Among 6 clusters, cluster-II was the largest with 28 genotypes followed by cluster-I and cluster-III with 10 and 5 genotypes respectively and cluster-IV, V \& VI each with two genotypes.

\section{Cluster means of characters}

The cluster means for the twenty characters studied in Rice genotypes revealed considerable differences among all the clusters. Cluster wise mean and over all cluster mean for the characters studied were presented in Table 3.

From the present data, it is evident that all the characters which represent earliness in rice like days to 50\% flowering (115.25 days) and days to maturity (137.6 days) having low values fall in cluster-VI and cluster-I respectively, whereas, cluster-II had the late in 50\% first flowering (120.53 days) and days to maturity (149.23 days). Plant height was recorded maximum in cluster-IV $(150.75 \mathrm{~cm})$ and minimum in cluster-II $(119.83 \mathrm{~cm})$. Number of panicles per plant was recorded 
maximum in cluster-V (14.95) and minimum in cluster-VI (1.96 g). Maximum panicle length was observed in cluster- VI $(27.62 \mathrm{~cm})$ and lowest panicle length was in cluster-V $(21.43 \mathrm{~cm})$. Maximum panicle weight was observed in cluster-IV (3.41) and minimum was observed in cluster-VI $(21.43 \mathrm{~cm})$. The cluster-III had the maximum number of primary branches per plant (13.3), whereas, cluster- $\mathrm{V}$ had the minimum number of primary branches per plant (9.75), with regards to number of secondary branches per plant maximum was recorded in cluster-III (36.36) and minimum was recorded in cluster$\mathrm{V}$ (23.6). Number of florets per panicle was recorded maximum in cluster-I (203.68) and minimum in cluster-IV (150.85). The genotypes of cluster- $\mathrm{V}$ had maximum number of grains per panicle (141.25), whereas genotypes of cluster-VI (84.82) had minimum number of grains per panicle. Fertility percentage was highest in cluster-V (84.39) and low was observed in cluster-VI (84.39). 1000 grain weight was highest in cluster-III (22.97 g) and minimum in clusterV (19.27 g). Highest grain length was observed in cluster-IV $(11.23 \mathrm{~mm})$ and lowest was recorded in cluster-I (8.79). Grain breadth was found to be highest in cluster-I $(2.7 \mathrm{~mm})$ and minimum was in cluster- $\mathrm{V}$ $(2.16 \mathrm{~mm})$. With respect to grain $\mathrm{L} / \mathrm{B}$ ratio, cluster-IV (4.55) found to be highest and cluster-III (3.24) found to be minimum. Highest kernel length was found to be maximum in cluster-IV $(8.62 \mathrm{~mm})$ and minimum was in cluster-V $(6.65 \mathrm{~mm})$. Maximum kernel breadth was in cluster-III $(2.46 \mathrm{~mm})$ and minimum was in cluster-IV $(2.46 \mathrm{~mm})$. Genotypes of cluster-IV (4.56) recorded maximum grain $\mathrm{L} / \mathrm{B}$ ratio and minimum was recorded in cluster-III (2.88) Harvest index was recorded highest in clusterIII $(45.29 \%)$ and minimum in cluster-IV $(38.85 \%)$. Seed yield per plant was highest in cluster-V (25.36 g) and minimum in clusterVI (19.24 g).

\section{Average intra and inter cluster distances}

The mean intra and inter cluster $\mathrm{D}^{2}$ values were calculated to assess the diversity among the six clusters are given in the Table 4 .

The intra cluster $\mathrm{D}^{2}$ value ranged from 202.51 to 684.04 .

The cluster-III had the maximum intra cluster $\mathrm{D}^{2}$ value (684.04) followed by Cluster-II (646.28) and cluster-I (630.83) revealing the existence of divergence genotypes that fall in these clusters, while it was least in cluster-IV (202.51) signifying the genotypes within this cluster were less genetically variable.

The inter cluster $\mathrm{D}^{2}$ values of the six clusters revealed that highest inter cluster generalized distance (1957.68) was between cluster- IV and cluster-V followed by cluster-III and IV (1954.27), cluster-I and IV (1779.21) and cluster-II and IV (1549.69) specifying that genotypes included in these clusters were genetically diverse and would give rise high heterotic response, while the lowest inter cluster was 587.86 found between cluster-I and cluster-V indicating close relationship among the genotypes included in these clusters.

The hybridization between genotypes of different clusters yields desirable genotypes. Recombination breeding between genotypes of different clusters has been reported by Singh et al., (1996) and Sinha et al., (1991).

Hence, the genotypes in cluster I viz., OR 2329-3, OR 1898-32-69-CN 12-12, CR 38151-1-1-1, CR 3607-11-2-1-1-3, OR 2380-2, CR 3856-44-22- 2-1-11, BRR 2031, MGD-1404, CR 2794-6-2-1 and OR 2330-1-1 had wider diversity with varieties CR 3844-1-1-4-1, CO 43 in cluster VI and these lines may be utilized in further breeding programme for the exploitation of hybrid vigour. 
Table.1 Analysis of variance for various characters in 49 genotypes of rice

\begin{tabular}{|c|c|c|c|c|}
\hline & & \multicolumn{3}{|c|}{ Source of variation with degrees of freedom (d.f.) } \\
\hline & & Replication (1) & Genotypes (48) & Error (48) \\
\hline 1 & Days to $50 \%$ maturity & 0.367 & $91.083 * *$ & 2.367 \\
\hline 2 & Days to maturity & 4.500 & $84.011 * *$ & 7.688 \\
\hline 3 & Plant height & 2.296 & $565.547 * *$ & 8.483 \\
\hline 4 & No of panicles per plant & 3.380 & $15.498 * *$ & 1.688 \\
\hline 5 & Panicle weight & 0.136 & $0.885 * *$ & 0.185 \\
\hline 6 & Panicle length & 0.013 & $18.545 * *$ & 1.15 \\
\hline 7 & No. of primary branches per panicle & 0.007 & $7.977 * *$ & 0.791 \\
\hline 8 & No. of secondary branches per panicle & 0.845 & $74.434 * *$ & 1.699 \\
\hline 9 & Number of Florets per panicle & 1245.718 & $3943.284 * *$ & 1906.244 \\
\hline 10 & Number of grains/panicle & 129.605 & $2034.469 * *$ & 788.028 \\
\hline 11 & Floret fertility $(\%)$ & 82.451 & $244.861 * *$ & 145.047 \\
\hline 12 & 1000 grain weight & 0.017 & $21.465 * *$ & 7.768 \\
\hline 13 & Grain length & 0.002 & $1.596 * *$ & 0.016 \\
\hline 14 & Grain breadth & 0.059 & $0.095^{*}$ & 0.014 \\
\hline 15 & Grain $\mathrm{L} / \mathrm{B}$ ratio & 0.128 & $0.561 * *$ & 0.033 \\
\hline 16 & Kernel length & 0.019 & $0.843 * *$ & 0.038 \\
\hline 17 & Kernel breadth & 0.004 & $0.128^{*}$ & 0.012 \\
\hline 18 & Kernel L/B ratio & 0.004 & $0.66^{* *}$ & 0.02 \\
\hline 19 & Harvest index & 0.674 & $28.695 * *$ & 0.289 \\
\hline 20 & Yield/ plant & 6.919 & $39.107 * *$ & 3.38 \\
\hline
\end{tabular}

Table.2 Distribution of 49 rice genotypes into six clusters

\begin{tabular}{|c|c|c|}
\hline $\begin{array}{l}\text { Cluster } \\
\text { number }\end{array}$ & $\begin{array}{l}\text { Number of } \\
\text { genotypes }\end{array}$ & Genotypes \\
\hline I & 10 & $\begin{array}{l}\text { OR 2329-3, OR 1898-32-69-CN 12-12, CR 3815-1-1-1-1, CR 3607-11-2-1-1-3, OR 2380-2, CR 3856-44-22- 2-1-11, BRR 2031, MGD- } \\
\text { 1404, CR 2794-6-2-1, OR 2330-1-1. }\end{array}$ \\
\hline II & 28 & $\begin{array}{l}\text { BRR 2002, CR 3808-55, NDR 40175-8, CN 1960-10-10, OR 2380-3, BRR 2028, MGD-1403, TTB 281-9-2-1, BRR 2030, CN 1740-19- } \\
\text { 550-11-15MLD 11-2, CRL 9-15-6-6-40-1, CN 1956-8-3, TTB 281-9-2-2-7, RP 5877-ME 80518, RP 5880-SACG 4, RP 5881- WEED } \\
\text { TOL. RICE1, Dhanarasi, CR 3696-1-2-2-1-1, CR 3607-8-1-2-1-1, CR 3697-3-2-2-2-1, OR 2552-2, CHR 25/CHK 02- 2-11-7-20-1-2-47, } \\
\text { CR 2683-7-1-2-2-3-2, Swarna sub-1, CR 2683-7-1-2-1-1, CR 3696-5-5-2-2-1, OR 2405-KK-27, CR 2683-45-1-2-1-1. }\end{array}$ \\
\hline III & 5 & NDR-40165-4, Local Check, CR 3505-2-1-2-2-1, CR 3607-12-1-1-1-2, CR 2681-2-3-1-1-1 \\
\hline IV & 2 & CR 3614-1-1-1-1-1, CR 3840-1-5-1-2-1 \\
\hline $\mathrm{V}$ & 2 & CR 3818-1-1-1-1-2, CO-43 Sub-1 \\
\hline VI & 2 & CR 3844-1-1-4-1, CO 43 \\
\hline
\end{tabular}


Table.3 Cluster mean values for various characters in forty nine rice genotypes

\begin{tabular}{|c|c|c|c|c|c|c|c|c|c|c|c|c|c|c|c|c|c|c|c|c|}
\hline $\begin{array}{c}\text { Genotype } \\
\text { Designation }\end{array}$ & 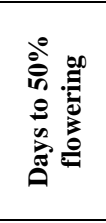 & 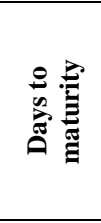 & 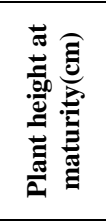 & 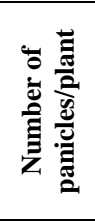 & 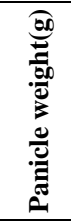 & 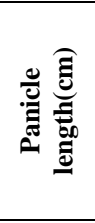 & 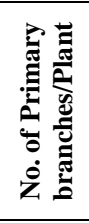 & 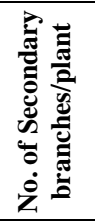 & 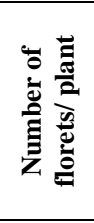 & 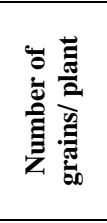 & 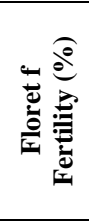 & 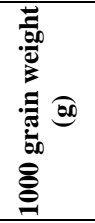 & 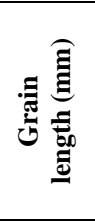 & 施 & 苞 & 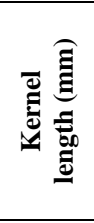 & 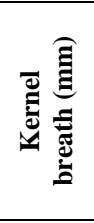 & 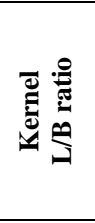 & 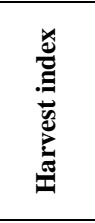 & 己 \\
\hline Cluster-I & 116.95 & 137.60 & 127.95 & 10.57 & 2.87 & 25.31 & 12.16 & 31.76 & 203.68 & 137.74 & 70.86 & 22.18 & 8.79 & 2.70 & 3.31 & 7.21 & 2.42 & 3.01 & 45.22 & 23.15 \\
\hline Cluster-II & 120.53 & 149.23 & 119.83 & 12.30 & 2.71 & 25.14 & 11.77 & 30.40 & 183.49 & 129.49 & 71.72 & 22.08 & 9.07 & 2.57 & 3.57 & 7.33 & 2.32 & 3.23 & 45.07 & 24.26 \\
\hline Cluster-III & 117.50 & 147.00 & 130.30 & 10.56 & 3.04 & 26.85 & 13.30 & 36.36 & 168.36 & 119.78 & 72.15 & 22.97 & 8.59 & 2.67 & 3.24 & 6.99 & 2.46 & 2.88 & 45.29 & 24.19 \\
\hline Cluster-IV & 116.50 & 145.25 & 150.75 & 9.55 & 3.41 & 24.25 & 9.80 & 28.45 & 150.85 & 108.85 & 77.15 & 27.55 & 11.23 & 2.48 & 4.55 & 8.62 & 1.95 & 4.56 & 38.85 & 22.41 \\
\hline Cluster-V & 120.25 & 149.25 & 121.50 & 14.95 & 2.10 & 21.43 & 9.75 & 23.60 & 166.85 & 141.25 & 84.39 & 19.27 & 8.18 & 2.16 & 3.93 & 6.65 & 2.17 & 3.09 & 43.77 & 25.36 \\
\hline Cluster-VI & 115.25 & 145.25 & 144.25 & 12.05 & 1.96 & 27.62 & 12.60 & 35.57 & 161.05 & 84.82 & 54.41 & 22.43 & 10.08 & 2.37 & 4.29 & 7.48 & 1.99 & 3.79 & 39.99 & 19.24 \\
\hline $\begin{array}{c}\text { Overall cluster } \\
\text { mean }\end{array}$ & 117.83 & 145.60 & 132.43 & 11.66 & 2.68 & 25.10 & 11.56 & 31.02 & 172.38 & 120.32 & 71.78 & 22.75 & 9.32 & 2.49 & 3.82 & 7.38 & 2.22 & 3.43 & 43.03 & 23.10 \\
\hline
\end{tabular}

Table.4 Average intra (bold) and inter-cluster D2 values for nine clusters among 49 genotypes of rice

\begin{tabular}{|l|l|l|l|l|l|l|}
\hline & Cluster-I & Cluster-II & Cluster-III & Cluster-IV & Cluster-V & Cluster-VI \\
\hline Cluster-I & $\mathbf{6 3 0 . 8 3}$ & 651.67 & 589.81 & 1779.21 & 587.86 & 1173.44 \\
\hline Cluster-II & & $\mathbf{6 4 6 . 2 8}$ & 708.82 & 1549.69 & 588.18 & 1066.14 \\
\hline Cluster-III & & & $\mathbf{6 8 4 . 0 4}$ & 1954.27 & 693.18 & 1262.09 \\
\hline Cluster-IV & & & & $\mathbf{2 0 2 . 5 1}$ & 1957.68 & 602.47 \\
\hline Cluster-V & & & & & $\mathbf{3 8 7 . 2 4}$ & 1288.07 \\
\hline Cluster-VI & & & & & & $\mathbf{8 4 5 . 9 8}$ \\
\hline
\end{tabular}

Table.5 Per cent contribution of important characters towards diversity in rice genotypes

\begin{tabular}{|c|c|c|c|c|c|c|c|}
\hline S. No. & Plant character & Times rank First & $\%$ contribution & S. No. & Plant character & Times rank First & $\%$ contribution \\
\hline 1 & Days to $50 \%$ flowering & 17 & 1.445 & 11 & Floret fertility (\%) & 0 & 0.001 \\
\hline 2 & Days to maturity & 0 & 0.001 & 12 & 1000 grain weight & 1 & 0.085 \\
\hline 3 & Plant height at maturity & 60 & 5.102 & 13 & Grain length & 158 & 13.435 \\
\hline 4 & No of panicles per plant & 5 & 0.420 & 14 & Grain breadth & 28 & 2.381 \\
\hline 5 & Panicle weight & 0 & 0.001 & 15 & Grain L/B ratio & 118 & 10.034 \\
\hline 6 & Panicle length & 18 & 1.530 & 16 & Kernel length & 0 & 0.000 \\
\hline 7 & No. of primary branches per panicle & 5 & 0.425 & 17 & Kernel breadth & 45 & 3.826 \\
\hline 8 & No. of secondary branches per panicle & 81 & 6.887 & 18 & Kernel L/B ratio & 9 & 0.765 \\
\hline 9 & Number of florets per panicle & 0 & 0.001 & 19 & Harvest index & 323 & 27.466 \\
\hline 10 & Number of grains per panicle & 1 & 0.085 & 20 & Seed Yield/plant & 307 & 26.105 \\
\hline
\end{tabular}




\section{Relative contribution of characters towards divergence}

The per cent contribution of important character towards divergence is presented in Table 5. It was observed that Harvest index and $(27.466 \%)$ and seed yield per plant $(26.105 \%)$ contributed maximum towards divergence, which accounted for $53.57 \%$ of total divergence.

Rest of the characters viz., Grain length $(13.435 \%)$, Grain L/B ratio (10.034\%), No. of secondary branches/panicle (6.887\%), Kernel breadth $(3.826 \%)$, Grain breadth (2.381\%), Panicle length (1.53\%), Days to 50 $\%$ maturity $(1.445 \%)$, Kernel L/B ratio $(0.7653 \%)$, No. of primary branches per panicle $(0.4252 \%)$ and No of panicles/plant $(0.42 \%)$ which contributed $46.25 \%$ towards total divergence.

Characters like 1000 grain weight, No. of grains per panicle, Days to maturity, Kernel length, Floret fertility (\%), Number of Florets /panicle and Panicle weight contributed negligible contribution, which accounted for $0.175 \%$ of total divergence.

Therefore, maximum emphasis should be given to the characters contributing to maximum $\mathrm{D}^{2}$ values in the clusters for the purpose of further selection and choice of parents for crossing programme.

\section{References}

Doddabhimappa, R., Gangapur, K., Thiyagarajan, Santosh K.M. and Malarvizhi, D. 2014. Genetic Diversity Analysis of Rice Genotypes for Yield and Yield Attributing Traits. Environment \& Ecology, 32 (3): 803807.

FAO, 2009. OECD-FAO Agricultural Outlook, 2009-2018.

Khan, A. S., Imran, M. and Ashfaq, M. 2009. Estimation of genetic variability and correlation for grain yield components in rice (Oryza sativa). AmericanEurasian Journal of Agriculture and Environmental Science, 6(5): 385-590.

Mahalanobis, P. C., 1936. On the generalized distance in statistics. Proceeding Naturnal Institute Science India. (2): 4955.

Rao, C.R., 1952. Advanced Statistical Methods in Biometrical Research. John Wiley \& Sons publishers, New York.

Sarawgi, A.K., and Rita, B. 2007. Studies on genetic divergence of aromatic rice germplasm for agro-morphological and quality characters. Oryza, 44: 74-76.

Venkatesan, M., Sowmiya, C. A., and ANBARASI, B. 2017. Studies on variability, heritability and genetic advance analysis in rice (Oryza sativa L.) under submergence. International journal of agricultural science, 13(1): 49-52.

\section{How to cite this article:}

Vangaru Sathish and Bijoy Kumar Senapati. 2017. Study of Genetic Diversity in Some Newly Developed Rice Genotypes. Int.J.Curr.Microbiol.App.Sci. 6(10): 2693-2698. doi: https://doi.org/10.20546/ijcmas.2017.610.317 